\title{
Blood pleurodesis for the medical management of pneumothorax
}

\author{
S Rinaldi, T Felton, A Bentley
}

The North West Lung Centre, University Hospital of South Manchester NHS Foundation Trust, Wythenshawe Hospital, Manchester, UK

Correspondence to: Dr A Bentley The North West Lung Centre, University Hospital of South Manchester NHS Foundation Trust, Wythenshawe Hospital, Manchester M23 9LT, UK; Andrew.Bentley@ manchester.ac.uk

Received 4 September 2007 Accepted 24 January 2008

\section{ABSTRACT}

Blood pleurodesis has been used to treat pneumothorax and persistent postoperative air leak following pneumonectomy. However, the indications for this procedure and the exact technique to be followed remain poorly defined. Having reviewed the current literature, a protocol is proposed for the technique and its complications and long-term outcomes are discussed.

Blood pleurodesis has been used for primary and secondary pneumothorax, ${ }^{1-7}$ persistent postoperative air leak ${ }^{8-11}$ and hydrothorax complicating peritoneal dialysis. ${ }^{12-14}$ However, good evidence supporting its use is lacking. Following a recent randomised controlled trial (RCT) of intrapleural instillation of autologous blood in the treatment of prolonged air leak after lobectomy, ${ }^{11}$ we review the evidence as to whether blood pleurodesis has a role in the management of pneumothoraces.

\section{METHODS}

A review of the literature up to December 2007 was performed using Medline and Embase databases with the search term "blood pleurodesis". References in the papers were examined to confirm that other relevant reports were not overlooked. Thirty papers were deemed relevant. There were no RCTs of blood pleurodesis in the management of pneumothorax and two RCTs relating to postoperative air leak. ${ }^{11}{ }^{15}$ One prospective nonrandomised case-control study examining blood pleurodesis in pneumothorax complicating acute respiratory distress syndrome (ARDS) ${ }^{6}$ and one investigating the intervention in spontaneous pneumothorax ${ }^{3}$ were also retrieved. All other publications were small case series.

\section{MECHANISM OF ACTION}

There is debate as to whether blood instillation into the pleural cavity causes a true pleurodesis or a "patch" effect whereby coagulated blood seals the site of the air leak. This latter view is supported by the rapid resolution of air leak observed in many studies, ${ }^{4816}$ occurring within a time scale shorter than can be explained by the development of pleural adhesions. Furthermore, in an animal model, gross inspection of rabbit pleura revealed no difference in inducing pleurodesis between blood instillation and chest tube control after 30 days. ${ }^{17}$

A systemic response, with fever and raised inflammatory markers, is often seen following pleurodesis. This correlates with success and does not necessarily indicate infection, ${ }^{18}$ although subclinical pleural infection theoretically remains a mechanism of action in blood pleurodesis.

\section{BLOOD PLEURODESIS IN PERSISTENT AIR LEAK (PAL) FOLLOWING PULMONARY RESECTION}

This was first described by Dumire in 1992 where a PAL of 5 weeks failed to resolve after tetracycline pleurodesis but ceased within $2 \mathrm{~h}$ of blood pleurodesis. ${ }^{4}$ Most of the subsequent literature consists of small case series. Although these may seem encouraging, with 111 of the 145 patients described experiencing cessation of their air leak following one instillation of blood (table 1), care needs to be taken in their interpretation. The lack of controls, coupled with the varying times over which patients were observed, raises the possibility that some air leaks may have resolved without further intervention.

Shackcloth randomised 20 patients with postoperative air leak of $>5$ days' duration to blood pleurodesis compared with continued conservative chest tube drainage. The investigator assessing air leak was blinded as to treatment group. There was a statistically highly significant reduction $(p<0.001)$ in "time to seal" the leak, time to chest drain removal and time to hospital discharge in the intervention group. ${ }^{11}$ Although the outcome measures may be viewed as subjective, they are defended as being "real-life" parameters used in determining patient management.

\section{BLOOD PLEURODESIS FOR THE MANAGEMENT OF PNEUMOTHORAX}

The place of blood pleurodesis in pneumothorax is less clear. Guidelines recommend that pleurodesis of any sort should only be used in patients with recurrent pneumothorax or PAL ( $>5$ days) who are unable to undergo surgery. ${ }^{19}$ This is based on the low recurrence rates $(0.4-2.3 \%)$ with surgical techniques compared with 10-25\% for tetracycline and $9 \%$ for talc pleurodesis. ${ }^{20-22}$ In comparison, recurrence rates for chest tube drainage alone are $35-41 \% .^{22}$

The literature on blood pleurodesis in the setting of spontaneous pneumothorax again consists largely of heterogeneous uncontrolled small case series from which it is difficult to draw conclusions. ${ }^{125-7}$ These reports give recurrence rates of $0-29 \%$, although the length of follow-up was often much less than the 4-5 years minimum in the talc and tetracycline studies (table 2). Only one controlled study exists, in which the recurrence rate was improved from $16 \%$ in controls to $0 \%$ in the blood pleurodesis group (at 12-48 months), the duration of tube drainage was reduced and the procedure was successful in $84 \%{ }^{3}$ The outcomes of the study are, however, weakened by its non-blinded design and non-random allocation of patients.

A recent controlled trail investigated blood pleurodesis for pneumothorax complicating 
Table 1 Success of blood pleurodesis in the setting of persistent air leak

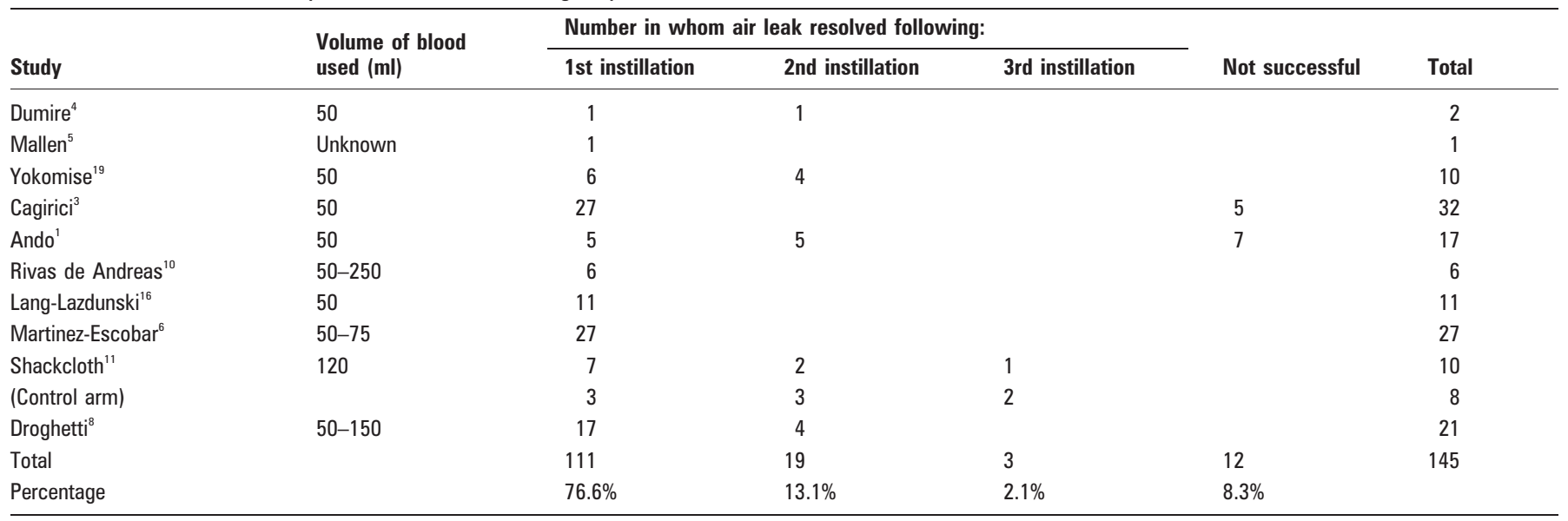

ARDS on the intensive therapy unit (ITU). In the intervention group there were statistically significant reductions in mortality, time to cessation of air leak, weaning time and ITU stay, as well as improvements in a number of physiological variables. However, non-random artificial pairing was used to create two "severity" matched groups and no mention is made of investigators being blinded to patient group, which is a concern given the subjective nature of some of the outcome measures. ${ }^{6}$

Although tetracycline is recommended as the first-line agent for medical pleurodesis in the BTS guidelines, its lack of availability - coupled with reports clarifying the risk of adverse effects with talc-led to the latter becoming increasingly used. ${ }^{19}{ }^{23}$ The previously feared complication of ARDS seems only to result from smaller particles found in non-calibrated talc and, if talc became a licensed medication in the UK, this concern should be ameliorated. ${ }^{23}{ }^{24} \mathrm{~A}$ review of the existing literature demonstrated a $91 \%(617 / 681)$ success rate for talc in pneumothorax. ${ }^{25} \mathrm{~A}$ more recent prospective study of thoracoscopic talc pleurodesis suggested a short-term failure rate of $5.1 \%$ and long-term recurrence of $5.4 \%$ over a median period of 118 months although, worryingly, $44 \%$ of the cohort were lost to follow-up. ${ }^{21}$

Only the most optimistic of studies suggest that blood pleurodesis reaches these levels of efficacy. The evidence supporting the use of this procedure is of poorer quality, and no direct comparison between the two agents exists. Nevertheless, blood pleurodesis has several theoretical advantages over the chemical techniques. It can be employed even if the lung is not fully expanded, reportedly causes less in the way of pleural thickening and adhesions, uses an agent which is always readily available, and there have been no reports of pain or long-term sequelae. ${ }^{151726}$ It is also the only non-surgical technique which has been associated with a rapid resolution of persistent air leak.
The previously held view that blood is the agent of choice for those requiring pleurodesis but likely to undergo future lung transplantation is, however, no longer valid. Initially, prior intrapleural procedures causing fusion of the pleural space were considered a contraindication to transplantation as haemorrhage from adhesions was associated with a high mortality. The "clam shell" incision, together with studies demonstrating no significant difference in surgical outcome for those with dense pleural adhesions, means this is no longer the case. ${ }^{27} 28$

\section{COMPLICATIONS}

Empyema is the most frequent complication reported with blood pleurodesis. In one study the incidence was $9 \% .^{3} \mathrm{~A}$ case report describing tension pneumothorax as a result of blood clotting in the tube in a patient with cystic fibrosis illustrates another potential complication. ${ }^{29}$ Avoiding narrow-bore chest tube $(12 \mathrm{~F})$ drainage and limiting repeat instillations of blood has been suggested to reduce complications.

\section{TECHNIQUE}

The technique was first described by Robinson in 1987. ${ }^{7}$ In this study of 25 patients with pneumothorax, $50 \mathrm{ml}$ heparinised blood was instilled into the pleural cavity on 1-3 occasions. No subsequent studies added heparin to the blood. This would seem sensible, given that early clotting of the blood may be an important mechanism of action. Prophylactic dose low molecular weight heparin is not thought to reduce the success rate. ${ }^{16}$ There are no studies to determine whether higher doses of anticoagulation render the procedure less effective.

The volume of blood used varies considerably. In the case of postoperative air leak, a recent RCT statistically confirmed the previous suspicion that $100 \mathrm{ml}$ is more effective than $50 \mathrm{ml} .{ }^{15}$

Table 2 Recurrence of pneumothorax following blood pleurodesis

\begin{tabular}{lclcl}
\hline Study & $\begin{array}{l}\text { No of } \\
\text { patients }\end{array}$ & $\begin{array}{l}\text { No of } \\
\text { recurrences }\end{array}$ & $\begin{array}{l}\text { Percentage } \\
\text { recurrence }\end{array}$ & $\begin{array}{l}\text { Length of follow-up } \\
\text { (months) }\end{array}$ \\
\hline Robinson $^{7}$ & 21 & 1 & 4.8 & $24-132$ \\
Mallen $^{5}$ & 1 & 0 & 0 & 16 \\
Blanco Blanco $^{2}$ & 17 & 5 & 29.4 & $17-41$ \\
Cagirici $^{3}$ & 32 & 0 & 0 & $12-48$ \\
Ando $^{1}$ & 11 & 2 & 18.2 & $2-24$ \\
Martinez-Escobar $^{6}$ & 27 & 0 & 0 & 12 \\
Total & 109 & 8 & 7.3 & \\
\hline
\end{tabular}


Box 1 Suggested protocol for blood pleurodesis for pneumothorax

\section{Indication}

- Persistent ( $>5$ days) air leak in patients with pneumothorax too unwell to undergo thoracic surgery (including ventilated patients with acute respiratory distress syndrome).

Equipment required (assuming chest drain in situ - preferably large bore)

- $2 \times 50 \mathrm{ml}$ syringe.

- Needle or cannula for phlebotomy.

- Sterile gloves.

- Sterilisation fluid (chlorhexidine or iodine).

- Two further sets of extension tubing for chest drain.

- Drip stand.

- Large saline flush.

- Spare chest drain.

\section{Procedure}

- Add two further sets of tubing connecting the chest drain to the underwater seal bottle.

- Take $100 \mathrm{ml}$ of the patient's own blood under aseptic conditions.

- Disconnect the drain from the extension tube (or, if already inserted, use a 3-way tap), sterilise and immediately inject the $100 \mathrm{ml}$ of patient blood into the drain.

- Loop the drainage tube over the drip stand.

- Avoid patient position rotation.

- After $4 \mathrm{~h}$, shorten drainage tube to its original length and leave overnight.

- If no further bubbling, perform chest radiograph to check for resolution.

- If bubbling continues, repeat the instillation of blood.

- Advise a limit of three instillations maximum.

Given the potential problem of thrombus in the tube causing tension pneumothrorax, authors have suggested transferring the blood from vein to pleural space quickly and subsequently flushing the tube with saline ${ }^{16}$ In case of emergency, it would also seem prudent to have a large saline flush and second chest drain available.

Patient rotation only makes a minimal difference to the distribution of radiolabelled tetracycline when there is a complex pleural space. ${ }^{30}$ As blood clots within minutes, rotation here would seem inappropriate and risk causing displacement of the chest tube.

Having reviewed the techniques described, we suggest the protocol shown in box 1 as the safest and most likely to lead to successful control of a persistent air leak, although this is merely an interpretation of imperfect literature.

\section{CONCLUSION}

The evidence supports the use of blood pleurodesis for persistent air leak following thoracic surgery, the only situation in which there is a prospective RCT. ${ }^{11}$ Blood pleurodesis has a limited role in the treatment of pneumothorax in those not suitable for surgical intervention-most notably in patients where talc pleurodesis has failed to arrest an air leak, where prompt resolution is desirable and in pneumothorax complicating ARDS. The optimum volume of blood to instil and the timing of the intervention have not been defined and long-term outcomes are not known because of the short follow-up in most reports. These questions are unlikely to be adequately answered without an RCT.

Acknowledgements: The authors acknowledge Dr Praveen Bhatia who initially suggested the topic for review.

Competing interests: None.

\section{REFERENCES}

1. Ando M, Yamamoto M, Kitagawa C, et al. Autologous blood-patch pleurodesis for secondary spontaneous pneumothorax with persistent air leak. Respir Med 1999; $93: 432-4$

2. Blanco BI, Sala BJ, Canto AH, et al. [Pleurodesis with autologous blood: the results of a series of 17 cases with more than a year of follow-up]. Rev Clin Esp 1997; 197:406-10

3. Cagirici U, Sahin B, Cakan A, et al. Autologous blood patch pleurodesis in spontaneous pneumothorax with persistent air leak. Scand Cardiovasc J 1998;32:75-8.

4. Dumire R, Crabbe MM, Mappin FG, et al. Autologous "blood patch" pleurodesis for persistent pulmonary air leak. Chest 1992;101:64-6.

5. Mallen JK, Landis JN, Frankel KM. Autologous "blood patch" pleurodesis for persistent pulmonary air leak. Chest 1993;103:326-7.

6. Martinez-Escobar S, Ruiz-Bailen M, Lorente-Acosta MJ, et al. Pleurodesis using autologous blood: a new concept in the management of persistent air leak in acute respiratory distress syndrome. J Crit Care 2006;21:209-16.

7. Robinson CL. Autologous blood for pleurodesis in recurrent and chronic spontaneous pneumothorax. Can J Surg 1987;30:428-9.

8. Droghetti A, Schiavini A, Muriana P, et al. Autologous blood patch in persistent air leaks after pulmonary resection. J Thorac Cardiovasc Surg 2006;132:556-9.

9. Lang-Lazdunski L, Coonar AS. A prospective study of autologous 'blood patch' pleurodesis for persistent air leak after pulmonary resection. Eur J Cardiothorac Surg 2004;26:897-900.

10. Rivas de Andres JJ, Blanco S, de la TM. Postsurgical pleurodesis with autologous blood in patients with persistent air leak. Ann Thorac Surg 2000;70:270-2.

11. Shackcloth MJ, Poullis M, Jackson M, et al. Intrapleural instillation of autologous blood in the treatment of prolonged air leak after lobectomy: a prospective randomized controlled trial. Ann Thorac Surg 2006;82:1052-6.

12. Catizone L, Zuchelli A, Zucchelli P. Hydrothorax in a PD patient: successful treatment with intrapleural autologous blood instillation. Adv Perit Dial 1991;7:86-90.

13. Hidai H, Takatsu S, Chiba T. Intrathoracic instillation of autologous blood in treating massive hydrothorax following CAPD. Perit Dial Int 1989:9:221-3.

14. Scarpioni R. Acute hydrothorax in a peritoneal dialysis patient: long-term efficacy of autologous blood cell pleurodesis associated with small-volume peritoneal exchanges. Nephrol Dial Transplant 2003;18:2200-1.

15. Andreetti C, Venuta F, Anile M, et al. Pleurodesis with an autologous blood patch to prevent persistent air leaks after lobectomy. J Thorac Cardiovasc Surg 2007:133:759-62.

16. Lang-Lazdunski L, Coonar AS. A prospective study of autologous 'blood patch' pleurodesis for persistent air leak after pulmonary resection. Eur J Cardiothorac Surg 2004;26:897-900

17. Mitchem RE, Herndon BL, Fiorella RM, et al. Pleurodesis by autologous blood, doxycycline, and talc in a rabbit model. Ann Thorac Surg 1999;67:917-21.

18. Ukale V, Agrenius V, Widstrom 0, et al. Inflammatory parameters after pleurodesis in recurrent malignant pleural effusions and their predictive value. Respir Med 2004:98:1166-72.

19. Henry M, Arnold T, Harvey J. BTS guidelines for the management of spontaneous pneumothorax. Thorax 2003;58(Suppl 2):ii39-52.

20. Alfageme I, Moreno L, Huertas C, et al. Spontaneous pneumothorax. Long-term results with tetracycline pleurodesis. Chest 1994;106:347-50.

21. Gyorik S, Erni S, Studler U, et al. Long-term follow-up of thoracoscopic talc pleurodesis for primary spontaneous pneumothorax. Eur Respir J 2007;29:757-60.

22. Light RW, O'Hara VS, Moritz TE, et al. Intrapleural tetracycline for the prevention of recurrent spontaneous pneumothorax. Results of a Department of Veterans Affairs cooperative study. JAMA 1990;264:2224-30.

23. Janssen JP, Collier G, Astoul P, et al. Safety of pleurodesis with talc poudrage in malignant pleural effusion: a prospective cohort study. Lancet 2007;369:1535-9.

24. MHRA. MHRA statement on talc preparations for pleurodesis. www.mhra.gov.uk/ publications/Safetywarnings/drugalerts/CON2032665 (accessed 10 0ct 2007).

25. Kennedy L, Sahn SA. Talc pleurodesis for the treatment of pneumothorax and pleural effusion. Chest 1994;106:1215-22.

26. Yokomise H, Satoh K, Ohno N, et al. Autoblood plus OK432 pleurodesis with open drainage for persistent air leak after lobectomy. Ann Thorac Surg 1998;65:563-5.

27. Dusmet M, Winton TL, Kesten S, et al. Previous intrapleural procedures do not adversely affect lung transplantation. J Heart Lung Transplant 1996;15:249-54.

28. Curtis HJ, Bourke SJ, Dark JH, et al. Lung transplantation outcome in cystic fibrosis patients with previous pneumothorax. J Heart Lung Transplant 2005;24:865-9.

29. Williams $\mathbf{P}$, Laing R. Tension pneumothorax complicating autologous "blood patch" pleurodesis. Thorax 2005;60:1066-7.

30. Lorch DG, Gordon L, Wooten S, et al. Effect of patient positioning on distribution of tetracycline in the pleural space during pleurodesis. Chest 1988;93:527-9. 